\section{Commentary: Interventions for mitral regurgitation: The sorting hat expands}

\author{
Stacey Chen, MD, and Eugene A. Grossi, MD
}

Mitral valve replacement (MVR) and repair (MVr) were the 2 gold standard therapies for regurgitation (MR). Although $\mathrm{MVr}$ is currently recommended as the first-line therapy for MR, ${ }^{1}$ the discussion of MVr versus MVR remains an area of ongoing debate. ${ }^{2,3}$ The short-term advantages of MVr over MVR have been well-documented in multiple studies demonstrating lower operative mortality, shorter postoperative hospital length of stay, and fewer valverelated complications such as thromboembolism and anticoagulation-bleeding. ${ }^{4}$ However, studies on the advantages of long-term outcomes of one technique over the other have not been as conclusive. ${ }^{5,6}$ In addition, there are a proportion of patients who are considered too sick to undergo either MVR or MVr. For these patients with surgically prohibitive risk, the MitraClip (Abbott Vascular, Abbott Park, Ill), which was approved for primary MR in 2013, has become a treatment option.

In this issue of the Journal, Zhou and colleagues ${ }^{8}$ present a retrospective analysis using the National Inpatient Sample dataset to study the trends in MVR, MVr, and the MitraClip system from 2000 to 2016 . Comparison between the number of overall and isolated MVRs and MVrs performed from 2000 to 2016 demonstrated a decrease in the number of MVRs with a concomitant increase in MVrs performed. Short-term outcomes between MVR and MVr patients were consistent with previous studies comparing the 2 techniques.

From 2013 to 2016, there was a proportionately greater increase in the use of the MitraClip per year relative to the increasing trend observed in MVrs. Interestingly, as noted by the authors, despite the continued annual increase

\footnotetext{
From the Department of Cardiothoracic Surgery, NYU Langone Health, New York, NY.

Disclosures: Authors have nothing to disclose with regard to commercial support.

Received for publication Feb 12, 2020; accepted for publication Feb 12, 2020; available ahead of print Feb 21, 2020.

Address for reprints: Eugene A. Grossi, MD, Department of Cardiothoracic Surgery, NYU Langone Health, 530 First Ave, Suite 9V, New York, NY 10016 (E-mail: eugene.grossi@nyulangone.org).

J Thorac Cardiovasc Surg 2021;162:563-4

$0022-5223 / \$ 36.00$

Copyright (c) 2020 by The American Association for Thoracic Surgery

https://doi.org/10.1016/j.jtcvs.2020.02.056
}

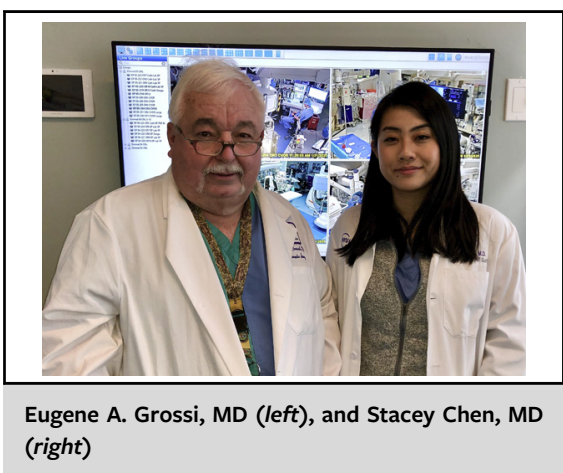

CENTRAL MESSAGE

The introduction of the MitraClip

has provided an additional tool

for multidisciplinary teams to

consider in their judicious evalu-

ation of patients with mitral

regurgitation.

in the number of MitraClip procedures performed, the number of overall mitral valve procedures (ie, surgical or transcatheter) has remained relatively unchanged. Instead, with the steady rise of MitraClip procedures, there has been a decline in the number of MVrs. Thus, although MitraClip recipients were older and sicker compared with patients who underwent surgical MVr, this would suggest that patients selected for the MitraClip may be high surgical risk candidates instead of surgically prohibitive risk. Just as in Hogwarts' school, the "Sorting Hat" process of the heart team evaluation has finer and perhaps more appropriate choices for a given patient. The addition of the MitraClip as a less-invasive treatment option now allows the multidisciplinary cardiothoracic team to further judiciously select the best treatment option for their patients with the most potentially optimal outcomes.

Zhou and colleagues ${ }^{8}$ also outlined trends within each of the mitral valve interventions for 3 separate time periods: 2000-2005, 2006-2011, and 2012-2016. They demonstrated that despite an overall trend of older patients with more comorbidities throughout the years, there was decreased in-hospital mortality and shorter lengths of stay across all treatment groups as well as a tendency for elective as opposed to emergent and/or urgent intervention. Improvement in surgical technique, patient selection, and understanding of mitral regurgitant pathophysiology has allowed for excellent short- and long-term patient outcomes regardless of the mitral valve intervention of choice. Rather than changing the landscape of mitral valve interventions, 
the MitraClip system has provided an additional armamentarium to the treatment of mitral valve disease.

\section{References}

1. Nishimura RA, Otto CM, Bonow RO, Carabello BA, Erwin JP III, Fleisher LA, et al. 2017 AHA/ACC Focused Update of the 2014 AHA/ACC Guideline for the Management of Patients With Valvular Heart Disease: A Report of the American College of Cardiology/American Heart Association Task Force on Clinical Practice Guidelines. J Am Coll Cardiol. 2017;70:252-89.

2. Hendrix RJ, Bello RA, Flahive JM, Kakouros N, Aurigemma GP, Keaney JF, et al. Mitral valve repair versus replacement in elderly with degenerative disease: analysis of the STS adult cardiac surgery database. Ann Thorac Surg. 2019;107: 747-53.

3. Jung JC, Jang MJ, Hwang HY. Meta-analysis comparing mitral valve repair versus replacement for degenerative mitral regurgitation across all ages. Am J Cardiol. 2019; $123: 446-53$
4. Lazam S, Vanoverschelde JL, Tribouilloy C, Grigioni F, Suri RM, Avierinos JF, et al. Twenty-year outcome after mitral repair versus replacement for severe degenerative mitral regurgitation: analysis of a large, prospective, multicenter, international registry. Circulation. 2017;135:410-22.

5. Silaschi M, Chaubey S, Aldalati O, Khan H, Uzzaman MM, Singh M, et al. Is mitral valve repair superior to mitral valve replacement in elderly patients? Comparison of short- and long-term outcomes in a propensity-matched cohort. J Am Heart Assoc. 2016;5(8).

6. Salmasi MY, Acharya M, Humayun N, Baskaran D, Hubbard S, Vohra H. Is valve repair preferable to valve replacement in ischaemic mitral regurgitation? A systematic review and meta-analysis. Eur J Cardiothorac Surg. 2016;50: 17-28.

7. Gossl M, Sorajja P. MitraClip patient selection: inclusion and exclusion criteria for optimal outcomes. Ann Cardiothorac Surg. 2018;7:771-5.

8. Zhou S, Egorova N, Moskowitz G, Giustino G, Gorav A, Acker M, et al. Trends in MitraClip, mitral valve repair, and mitral valve replacement from 2000-2016. J Thorac Cardiovasc Surg. 2021;162:551-62.e4.
See Article page 551.

\section{Commentary: Trends in mitral valve interventions: The good, the bad, and the ugly}

\author{
Davide Pacini, MD, $\mathrm{PhD}$, and \\ Giacomo Murana, MD, PhD
}

After the burden of transcatheter aortic valve implantation, mitral valve regurgitation has become the most common valve-related disease requiring surgical correction. ${ }^{1}$ Two main innovations have dramatically changed the landscape of mitral valve intervention. The first, introduced in 1983, was the so-called French correction that represented the dawn of mitral repair. The second was the advent of the MitraClip device (Abbott Laboratories, Abbott Park, Ill) in 2013, leading to percutaneous mitral valve interventions that allow us to treat sicker patients. The evolution of this new concepts become an evident recommendation of the latest American Heart Association/American College of Cardiology guidelines ${ }^{2}$ where mitral vale repair is the preferred technique when a successful and durable repair can be accomplished despite symptoms, age, or

From the Cardiac Surgery Unit, Cardio-Thoraco-Vascular Department, S. Orsola Hospital, University of Bologna, Bologna, Italy.

Disclosures: Authors have nothing to disclose with regard to commercial support.

Received for publication Jan 15, 2020; accepted for publication Jan 24, 2020; available ahead of print Feb 4, 2020.

Address for reprints: Davide Pacini, MD, PhD, Cardiac Surgery Unit, CardioThoraco-Vascular Department, S. Orsola Hospital, University of Bologna, Via Massarenti 9, 40138 Bologna, Italy (E-mail: davide.pacini@aosp.bo.it).

J Thorac Cardiovasc Surg 2021;162:564-5

$0022-5223 / \$ 36.00$

Copyright $($ c 2020 by The American Association for Thoracic Surgery

https://doi.org/10.1016/j.jtcvs.2020.01.049
Check for updates

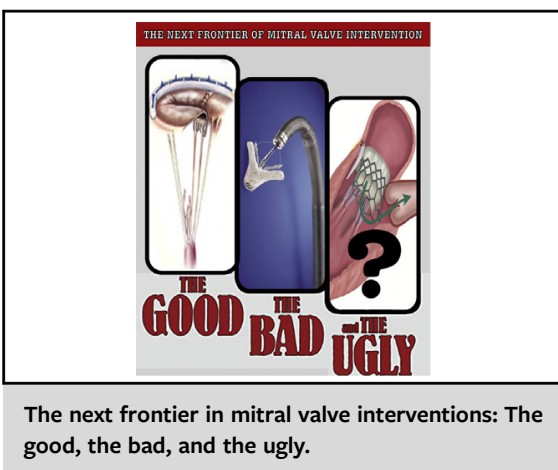

CENTRAL MESSAGE

Mitral valve interventions are

associated with excellent surgical

results making them the next

frontier for percutaneous

approaches.

comorbidities and a MitraClip is indicated (only in primary mitral regurgitation) in favorable anatomy when patients have prohibitive surgical risk.

Zhou and colleagues ${ }^{3}$ elucidate the trends and outcomes of 656,030 mitral valve interventions in 44 states participating in the Nationwide Inpatient Sample administrative database. They analyzed the trends in patient characteristics, focusing on comorbidities and, thus, on the preoperative risk. During the past 2 decades, the number of replacements decreased significantly by $5.6 \%$ per year, whereas repair increased by $8.4 \%$ per year and MitraClip 